\title{
Some problems in microscopy encountered in clinics for sexually transmitted disease
}

\author{
F. J. AUMONIER \\ From St Mary's Hospital, London
}

SUMMARY The actual field diameter of 24 microscopes used in clinics for sexually transmitted diseases has been measured by means of a stage micrometer. The variation in findings is given, and the difficulties in producing accurate measurements are discussed.

\section{Introduction}

It is an accepted truth that accurate measurements of selected parameters are essential to the scientific study of problems. For this to be achieved it is necessary for the units of measurement to be constant in different laboratories and for different observers. In the days when the cubit was the accepted unit of length and was defined as the length of the king's forearm, difficulties could arise when a new king was crowned.

A commonly accepted method of assessing the severity of urethritis is to quote the number of leucocytes found in a 'high power field'. Unfortunately, this unit suffers from some of the disadvantages of the cubit.

The edge of the field of the microscope is an image of the stop within the eyepiece. The actual diameter of the field, expressed in micrometers, will depend on the total magnification which is the product of the eyepiece and objective magnifications, and in some instruments this must be increased by the magnification factor of the binocular head. A further complication is that eyepiece design may affect the field size; for example, a Huyghens $\times 8$ eyepiece may have a smaller field than a wide field $\times 10$ eyepiece.

\section{Methods}

By courtesy of the staff it has been possible to measure the actual field diameter of the microscopes used in five major clinics in central London and in two in the home counties. Measurements were carried out with a stage micrometer.

Address for reprints: Dr F. J. Aumonier, Praed Street Clinic, St Mary's Hospital, London W2

Received for publication 30 March 1978

\section{Results and comment}

A total of 24 instruments was studied. The results are shown in the Table. The extreme variation of field diameter was from $112 \mu \mathrm{m}$ to $190 \mu \mathrm{m}$, so that if the same specimen was studied a count of 20 cells in a field of $112 \mu \mathrm{m}$ would be given as 57 cells per field of $190 \mu \mathrm{m}$.

For some of the instruments two values for the field size are given. In these microscopes the interocular distance of the binocular head is regulated by moving the eyepiece tubes along a horizontal slideway; this has the effect of varying the tubelength and, consequently, the magnification. This error is not too serious since the value of 20 cells per minimum field would only be reported as 24 cells per maximum field. In those instruments which have a single value the interocular distance is adjusted by pivoting the eyepiece tubes in the manner used for field-glasses; this mechanism maintains a constant tubelength and the magnification is unaltered.

A further complication is that in several of the instruments the outer zone of the field had very poor definition, which could not be improved by careful focusing, and was therefore due to lack of correction of spherical aberration in the outer zone of the objective.

It would seem that if cell counts are to serve any useful purpose the field size must be standardised. The simplest method would be to use a square field stop or graticule in the eyepiece, as in the Ehrlich eyepiece. This would have to be calibrated against a stage micrometer, a task which could be done by the service mechanics during routine maintenance. Hopefully the cost might not be prohibitive, and the venereologist's field would then have a more constant basis than the royal cubit. 
Detailed findings in 24 microscopes studied*

\begin{tabular}{|c|c|c|c|c|c|c|c|}
\hline \multirow[b]{3}{*}{ Microscope no. } & \multirow[b]{3}{*}{ Eyepiece } & \multicolumn{3}{|c|}{ Diameter of field $(\mu \mathrm{m})$} & \multicolumn{3}{|c|}{ Area of field $\left(\mu m^{2}\right)$} \\
\hline & & \multirow[t]{2}{*}{ Single value } & \multicolumn{2}{|c|}{ Double value } & \multirow[t]{2}{*}{ Single value } & \multicolumn{2}{|c|}{ Double value } \\
\hline & & & Min. & Max. & & Min. & $\operatorname{Max}$. \\
\hline $\begin{array}{l}1 \\
2\end{array}$ & $\begin{array}{l}\text { Huyghens } \times 6 \\
\text { Wide field } \times 6\end{array}$ & $\begin{array}{l}170 \\
172\end{array}$ & & & $\begin{array}{l}22698 \\
23235\end{array}$ & & \\
\hline 3 & Periplan $\times 6$ & & 159 & 168 & & 19856 & 22167 \\
\hline 4 & Huyghens $\times 6$ & & 172 & 190 & & 23235 & 28353 \\
\hline 5 & Huyghens $\times 6$ & & 140 & 158 & & 15399 & 19609 \\
\hline 6 & Huyghens $\times 8$ & 125 & & & 12272 & & \\
\hline 7 & Huyghens $\times 8$ & & 173 & 185 & & 23506 & 26880 \\
\hline 8 & Compensating $\times 8$ & & 155 & 165 & & 18869 & 21383 \\
\hline 9 & Huyghens $\times 8$ & 120 & & & 11310 & & \\
\hline 10 & Huyghens $\times 8$ & & 180 & 190 & & 25447 & 28353 \\
\hline 11 & Huyghens $\times 8$ & & 175 & 180 & & 24053 & 25447 \\
\hline 12 & Huyghens $\times 8$ & & 164 & 170 & & 21124 & 22698 \\
\hline 13 & Huyghens $\times 8$ & & 115 & 120 & & 10387 & 11310 \\
\hline 14 & Huyghens $\times 8$ & & 112 & 119 & & 9852 & 11122 \\
\hline 15 & Compensating $\times 8$ & 138 & & & 14957 & & \\
\hline 16 & Wide field $\times 10$ & 156 & & & 19113 & & \\
\hline 17 & Wide field $\times 10$ & 161 & & & 20358 & & \\
\hline 18 & Periplan $\times 10$ & & 180 & 190 & & 25447 & 28353 \\
\hline 19 & Periplan $\times 10$ & & 173 & 183 & & 23506 & 26302 \\
\hline 20 & Compensating $\times 10$ & 153 & & & 18358 & & \\
\hline 21 & Huyghens $\times 10$ & & 170 & 172 & & 22698 & 23235 \\
\hline 22 & Compensating $\times 10$ & & 150 & 165 & & 17671 & 21383 \\
\hline 23 & Wide field $\times 10$ & & 168 & 178 & & 22167 & 24885 \\
\hline 24 & Compensating $\times 12.5$ & 170 & & & 22698 & & \\
\hline
\end{tabular}

*All the instruments were equipped with oil immersion objectives of simple achromatic type, except Nos. 20 and 24, which had flat field achromats. In all cases these were $\times 100$ magnification.

Further difficulties arise when the texture of the smears is considered. Such preparations are rarely uniform in cellular distribution. For this reason a quick survey of the whole smear should be made under a low power before any count is attempted. Since some microscopes are only equipped with an oil immersion objective, this cannot always be done. Naturally, when the pressure of work is great there is a temptation for the technician to use the high power at once; if the smear is very scanty this may account for a few of the reports of 'nil on slide after staining'. 